\title{
UNA DECISIÓN PASIVA \\ DERRIDA Y ROSENZWEIG FRENTE A LA SOBERANÍA DE LA RAZÓN
}

\author{
Miriam Jerade ${ }^{1}$ \\ UNAM, Facultad de Filosofía y Letras
}

Recibido: 02.10.2019 - Aceptado: 04.12.2019

\begin{abstract}
RESUMEN
El presente artículo busca mostrar la manera en que dos pensadores judíos del siglo XX, Franz Rosenzweig y Jacques Derrida permiten pensar lo político, e incluso lo teológico político, más allá de la soberanía. Para ello leeré la noción de decisión pasiva de Derrida como alteridad y alteración de la razón a partir de la noción de Revelación que Franz Rosenzweig desarrolla en La estrella de la redención. En un segundo momento, expondré la deconstrucción de la soberanía a partir de otro punto en común entre los dos pensadores: la noción de una violencia intrínseca al derecho y la concepción de una política mesiánica.
\end{abstract}

Palabras clave: Soberanía; Racionalidad; Revelación; Mesianismo.

\begin{abstract}
This article seeks to show how two twentieth-century Jewish philosophers, Franz Rosenzweig and Jacques Derrida, allows us to think the political, and even the theologico-political, beyond sovereignty. In order to do so, I will read the notion of Derrida's passive decision as alterity and alteration of reason based on the notion of Revelation that Franz Rosenzweig develops in The Star of Redemption. In a second moment, I will expose the deconstruction of sovereignty from another common point between the two thinkers: the notion of a violence intrinsic to law and the conception of a messianic politics.
\end{abstract}

Keywords: Sovereignty; Rationality; Revelation; Messianism.

\footnotetext{
${ }^{1}$ miriamjerade@gmail.com
} 


\section{INTRODUCCIÓN}

En las páginas conclusivas de Canallas: Dos ensayos sobre la razón (2003), en el capítulo intitulado Llegar-A los fines del Estado (y de la guerra y de la guerra mundial), Jacques Derrida escribe:

Lo que hay que pensar aquí es esa cosa inconcebible o desconocida, una libertad que ya no sería el poder de un sujeto, una libertad sin autonomía, una heteronomía sin servidumbre, en suma, algo como una decisión pasiva.(Derrida 2005, 182)

A partir de esta crítica que Derrida hace al filosofema de la decisión que define con el término de decisión pasiva, expondremos la deconstrucción de la soberanía como alteridad y alteración de la razón a partir de la noción de Revelación que Franz Rosenzweig desarrolló en La estrella de la redención. Con la noción de decisión pasiva, Derrida opera una deconstrucción de la razón entendida como soberana, es decir, una que decide y es el fundamento de la acción; lo que obliga a poner en cuestión tanto la noción de libertad como la de poder y, por supuesto, la cópula actividad-pasividad. Ya en Fuerza de ley, en origen una conferencia impartida en la Cardozo Law School en 1989, Derrida proponía una deconstrucción de la decisión en lo que describió como la experiencia de lo indecidible, que se parece mucho al análisis que hace en Canallas sobre una suspensión de lo calculable en el proceso de la decisión, al sostener que ni la responsabilidad ni la decisión pueden estar justificadas o fundadas en el conocimiento o en el cálculo: "Indecidible es la experiencia de lo que siendo extranjero, heterogéneo con respecto al orden de lo calculable y de la regla, debe sin embargo - es de un deber de lo que hay que hablar - entregarse a la decisión imposible, teniendo en cuenta el derecho y la regla."(Derrida 2002, 55)

Los dos párrafos antes citados apelan al deber, tienen la forma de una inyunción ética sobre lo que "hay que pensar" y, en los dos casos, Derrida formula gramaticalmente una estructura mesiánica sobre algo que está por-venir, un porvenir de la justicia o de la razón. Es importante señalar que ni la decisión pasiva ni la experiencia de lo indecidible son una apología del irracionalismo ${ }^{2}$, sino que,

2 Tampoco la filosofía de Rosenzweig lo es. En las observaciones adicionales a la Estrella de la Redención (1925) conocidas como "El nuevo pensamiento" Rosenzweig escribe sbre "[d]el peligro de entender el nuevo pensamiento en el sentido (más bien sin-sentido) de las tendencias 'filosófico-vitales' o ‘irracionalistas' de cualquier otro tipo.’(Rosenzweig 1989, 72) 
según lo describe en Canallas, se trata de "la única oportunidad para pensar, racionalmente, algo como un porvenir y un devenir de la razón" (Derrida 2005, 172). De hecho, el capítulo que clausura Canallas inicia con una pregunta por la historia de la razón, por su devenir continuo y diferenciado, por el hecho de que la razón ha sido concebida desde la tradición del Iluminismo como soberana: "quiere ser ella misma; ésta es su ipseidad soberana." (189) Mientras que la decisión pasiva, como una libertad sin autonomía, implica reconocer una alteridad al interior de la razón que proponemos leer junto con la Revelación rosenzweigiana. Inclusive afirma: "habría que pensar racionalmente una hiper-ética o una hiper-política" (p.182) por encima, pero nunca divorciada, de la ley, del deber y de la deuda. Es a partir de este eco de la revelación en la decisión pasiva que quisiera sugerir un diálogo entre Rosenzweig y Derrida, entre la metaética del primero y la ética hiperbólica del segundo, que tendrían en común plantear una alteridad al interior de la razón que, para los dos filósofos, conduce a una crítica de la soberanía.

En Canallas, Derrida relaciona la crítica de la razón con la deconstrucción de la soberanía en dos niveles: del sujeto en tanto que sí-mismo y del Estadonación. Por un lado, una decisión pasiva es una crítica al sujeto, pues toda decisión presupone un compromiso activo de la racionalidad y un agente capaz de deliberar. La decisión pasiva conlleva por lo tanto la crítica a la noción de autonomía como poder de gobernarse a sí mismo y, por ende, un distanciamiento de la ética kantiana, de la razón práctica y de la metafísica del libre arbitrio. Por otro lado, hace un señalamiento a la noción schmittiana de soberanía como decisión activa sobre el estado de excepción. Si bien, como explica en ese mismo texto, no era necesario que Schmitt lo enunciara ya que, analíticamente, la concentración de fuerza y la excepción absolutas permiten deducir esta suspensión del derecho de este concepto político-jurídico que, recuerda Derrida: "seculariza una herencia teológica"(Derrida 2005, 184). Esta herencia onto-teológica de la soberanía es su incondicionalidad, su unidad indivisible que hace una analogía con Dios pensado como unidad. ${ }^{3}$ Por otro lado, tanto Rosenzweig como Derrida, aunque también Benjamin, plantean un antagonismo con la teología política de Schmitt y el estado de excepción como suspensión del derecho, ya que para los filósofos judíos la anomia entendida en términos de redención y mesianismo es la destrucción del poder soberano que Schmitt legitima y que analizaremos en la segunda parte de este artículo a partir de la política mesiánica.

${ }^{3}$ En Y mañana qué..., Derrida escribe sobre esta herencia onto-teológica: “Omnipresente en nuesto discurso y nuestros axiomas, bajo su nombre o bajo otro, propiamente o figurado, ese concepto es de origen teológico: el verdadero soberano es Dios. El concepto de esta autoridad o de esta potencia fue transferido al monarca como 'derecho divino'. Luego la soberanía fue delegada al pueblo, en democracia, o a la nación, con los mismos atributos teológicos que aquellos atribuidos al rey y a Dios. Hoy, en todas partes donde se pronuncia la palabra soberanía, es herencia permanece innegable, no importa qué diferenciación interna se le reconozca."(Derrida y Roudinesco 2009, 104) 
Intentaré explorar un posible diálogo entre Rosenzweig y Derrida para pensar ese imposible derridiano de una incondicionalidad sin soberanía a partir de una alteridad o alteración de la razón. El primer intento será leer la noción de una libertad sin autonomía y una heteronomía sin servidumbre en paralelo a la noción de Revelación en Rosenzweig. El segundo, analizar la crítica de la racionalidad tanto en Rosenzweig como en Derrida a partir de la política mesiánica como una crítica de la soberanía, pero también como un exceso que abre a la razón y a la ipseidad al por-venir de la justicia. Una justicia que se podría resumir con la frase de Derrida, "la posibilidad de lo imposible" porque excede tanto a la política como al derecho. Es un resto diferencial entre la justicia en el orden del derecho y la justicia mesiánica ${ }^{4}$.

Habría un tercer punto de contacto que no desarrollaré en el presente artículo, si bien es el único aspecto de la filosofía de Rosenzweig que Derrida elaboró explícitamente. Sobre la pregunta por la incondicionalidad sin soberanía, que es también la máxima de una racionalidad responsable, Derrida dio como una posible respuesta al final de Canallas “[...] la invención poética de un idioma cuya singularidad no cedería a ningún nacionalismo [...]” (Derrida 2005, 188) lo que hace eco a algunas reflexiones sobre Rosenzweig, tanto el análisis en la larga nota a pie de página de El monolingüismo del otro sobre la lengua sagrada ${ }^{5}$ como a la lectura puntual de la carta de Scholem a Rosenzweig que publicó con el título "Los ojos de la lengua - el abismo y el volcán"6, una confesión sobre las preocupaciones de Scholem en torno a lengua hebrea que era parte de un portafolio que en diciembre de 1926 organizó con otros amigos como un tributo epistolario al filósofo de Kassel en su 40 cumpleaños, él quien tendría una gran distancia con el proyecto de hacer del hebreo una lengua nacional.

Dichas lecturas sobre Rosenzweig son también una crítica a la noción de soberanía, pues la alteridad e inclusive el extrañamiento que el pueblo eterno introduce en la lengua del anfitrión, como el Yidish en el Alemán o el Ladino en el

\footnotetext{
${ }^{4}$ Agradezco a Roberto Navarrete haberme hecho hincapié en este aspecto que relaciona nuevamente a Derrida y a Rosenzweig.

${ }^{5}$ Me permito remitir al lector a mi artículo (Jerade 2015) donde analizo puntualmente la nota a pie de página sobre lo que sería el monolingüismo del huésped.

${ }^{6}$ Ver Les yeux de la langue. L'abîme et le volcan, Paris, Galilée, 2012. La carta de Scholem a Rosenzweig de 1926, fue encontrada por Stéphane Mosès quien la publicó en 1985. No hay ninguna seguridad de que Rosenzweig la haya leído si bien en diciembre de 1926 Rosenzweig escribe a Buber que ha recibido el portafolio en el cual Scholem contribuye con su carta y el 29 de diciembre le escribe a Martin Goldner que ha leído casi la totalidad del portafolio. Empero, no tenemos ningún dato sobre la reacción de Rosenzweig a la carta. Agradezco a Martin Kavka esta información. Existe una versión en español de la versión del texto de Derrida publicada en Le Cahier de l'Herne Derrida traducida por Jazmín Acosta en la revista Nombres, num 24, 2010.
} 
Español, confrontan el fantasma de la unidad de la lengua nacional ${ }^{7}$. En El monolingüismo del otro, Derrida afirma: "Toda cultura se instituye por la imposición unilateral de alguna 'política de la lengua"'(Derrida 1997, 73). Una nación o una comunidad cultural, una comunidad lingüística, suspende el principio de hospitalidad para garantizar la propiedad de lo propio, y esta es también una de las tareas del poder soberano, además de la unificación del control del territorio y sus fronteras, la de la homogenización de la lengua.

No obstante, no se trata de una simple comparación o parataxis entre textos de los dos autores, Derrida había leído a Rosenzweig y bebía de esa herencia filosófica también a través de la obra de Levinas quien en el Prefacio de Totalidad e infinito aseveró “[...] Der Stern der Erlösung de Franz Rosenzweig, demasiado presente en este libro como para ser citado." (Levinas 2002, 54) Derrida, en distintas ocasiones, asume la herencia levinasiana en su filosofía, no sin distanciarse de ciertas posiciones políticas del filósofo lituano ${ }^{8}$. No obstante, a mi parecer, tanto Rosenzweig como Derrida tienen un pensamiento político distante al de Levinas, que no está simplemente fundado en la justicia por el tercero sino en una suspensión de la ley que lleva a pensar de otro modo la excepción como interrupción de la sobernía. No deja empero de sorprender que Derrida apenas mencione a Rosenzweig - esto lo digo consciente de que en el seminario aún inédito intitulado "Nationalités et nationalismes philosophiques" sobre la psique judeo-alemana Derrida dedica varias sesiones al filósofo de Kassel.

Desconcierta que no haga ninguna alusión a La estrella de la redención en Fuerza de ley de 1994 si bien lo hace extensamente en $\mathrm{El}$ monolingüismo del otro dos años más tarde. Sorprende, porque en la segunda parte de Fuerza de Ley hace una lectura de la "Crítica de la violencia" de Benjamin, que es muy similar a ciertos planteamientos de La estrella de la redención sobre la violencia de la ley, aunque no se sabe bien, tratándose de dos textos publicados el mismo año, 1921, quién influyó a quién, si Rosenzweig a Benjamin o viceversa. Derrida tampoco hace alusión al filósofo de Kassel cuando habla de la justicia y de mesianismo, si bien en los dos casos, lo hace a partir de textos de Benjamin. Es importante subrayar que tanto Rosenzweig como Benjamin entienden lo mesiánico como una posibilidad radical de destrucción del poder soberano en nombre de una justicia que no es equivalente al derecho, si bien quizás con salidas distintas, el primero a partir de un tiempo mesiánico que tiene la forma de un estado de excepción que irrumpe catastróficamente en la historia y suspende la normatividad jurídica, una

7 “'El pueblo eterno ha perdido su lengua propia (seine eigene Sprache verloren hat)', 'habla en todas partes la lengua de sus destinos exteriores, la lengua del pueblo con el que reside como huésped (bei dem es etwa zu Gaste wohnt)"'. (Rosenzweig 1997, 359)

${ }^{8}$ Distanciamiento con el pensamiento político de Levinas, que Derrida expresó en distintos momentos. Ver por ejemplo (Derrida 1998) y la entrevista concedida a Le magazine littéraire en abril de 2003, URL de referencia: https:/www.nouveau-magazine-litteraire.com/derrida-aveclévinas-«-entre-lui-et-moi-dans-laf- fection-et-la-confiance-partagée-» [consultado 30/septiembre/2019] 
violencia divina que lleva la insignia de la justicia. Mientras que, para Rosenzweig, la redención es una vivencia del tiempo mesiánico sobre el histórico como una afirmación de la Creación y de la Revelación como el acontecimiento del llamado a la unicidad de cada uno; el papel que cada uno, aunque a coro, tiene en la Redención. No obstante, si bien Derrida piensa la justicia en términos de acontecimiento como Benjamin, podríamos decir que es próximo a Rosenzweig en cuanto a pensar una política desde la singularidad.

Relacionar la filosofía de Derrida con la de Rosenzweig nos permitirá mostrar que los dos pensadores judíos permiten pensar lo político, e incluso lo teológico-político, más allá de la soberanía. Esto último contradice las interpretaciones más tradicionales de Rosenzweig, siendo la más ejemplar la de Nahum Glatzer de 1953, que quisieron ver en su obra una filosofía ahistórica y apolítica a favor de la vida litúrgica. Estudios más recientes como los de Leora Banitzky, Benjamin Pollock y Peter Eli Gordon han sabido leer el pensamiento político de Rosenzweig, comenzando por su crítica al paganismo del estado-nación, reconociendo el compromiso social y político con el mundo en la labor histórico-universal de la Redención. En español Roberto Navarrete Alonso ha hecho un trabajo loable tanto de traducción de obras importantes de Rosenzweig como de exégesis, subrayando la dimensión política de su filosofía, comparándolo con Carl Schmitt ${ }^{9}$. Eric Santner y Bonnie Honig han explorado la idea del milagro al interior de la vida cotidiana ${ }^{10}$. De acuerdo con Honig, la teología del milagro puede ser la oportunidad de pensar la política de emergencia en el estado de excepción, en términos más democráticos que el deseo schmittiano de salvaguardar la soberanía. Por su parte, Miguel Vatter sostiene que la teología política de Rosenzweig - así como la de Hermann Cohen - niega la prioridad asignada al estado-nación en la política moderna a favor del cosmopolitismo y del republicanismo. Vatter sostiene que la política mesiánica de Rosenzweig al relacionar al pueblo con el Estado de derecho disocia a este último de la soberanía ${ }^{11}$.

Dana Hollander es quizá la única académica que ha dedicado una obra a las interacciones entre Rosenzweig y Derrida a partir de las nociones de ejemplaridad y elección como la manera de entender una historia abierta a la alteridad y al futuro. Sin embargo, me parece que hay en la noción derridiana de decisión pasiva otra manera de acercarlo a Rosenzweig y a su anti-estatismo que constituye una crítica no sólo del nacionalismo como ella bien mostró, sino también de la soberanía.

\footnotetext{
${ }^{9}$ (Glatzer 1961; Batnitzky 2000; Pollock 2014b; Gordon 2003; Navarrete Alonso 2017b)

${ }^{10}$ (Santner 2005; Honig 2007; 2009)

${ }^{11}$ (Vatter 2016)
} 


\section{REVELACIÓN Y DECISIÓN PASIVA}

La gran apuesta filosófica del pensamiento político de Derrida es la de disociar soberanía de incondicionalidad en nombre de la razón, pero de un acontecimiento de la razón, de un por-venir de la razón. Esta disociación de la soberanía y la incondicionalidad implicaría una puesta en cuestión de la "compulsión o la autoposición de soberanía (que es asimismo, nada menos, la de la ipseidad misma, del mismo del sí mismo [meisme, de metipsissimus, meisme], ipseidad que conlleva, como lo confirmaría también la etimología, la posición de poder [...] la potencia de lo mismo, del ipse como sí mismo [...] "(Derrida 2005, 170). La relación que hace Derrida de la soberanía con la ipseidad lo llevará a la noción de acontecimiento como la incalculable llegada del otro. La Revelación en Rosenzweig implica tanto la idea de manifestarse al otro, como la de abrirse al llamado del otro (en alemán Offenbarung remite a una apertura). No obstante, la Revelación supone principalmente una alteración del sí-mismo ${ }^{12}$, una pasividad de quien es llamado que no es inactiva ${ }^{13}$. La pasividad - que es el corazón de la decisión pasiva- en el sentido de ruptura con la posición de poder como ipse, podría muy bien relacionarse con este planteamiento de la deconstrucción.

Un aspecto que Derrida señala en una nota a pie de página en el capítulo final de Canallas me parece podría hacer un puente entre la deconstrucción y el proyecto filosófico de Rosenzweig, si bien ahí se contrapone a Lutero con Heidegger: "He recordado con frecuencia, por lo demás, que el motivo y la palabra Destruktion designaba, en Lutero, una desedimentación de la teología instaurada (se podría decir igualmente de la onto-teología) con el fin de retornar a una verdad más originaria de las Escrituras" (Derrida 2005, 179, nota 4). Derrida afirma que a pesar del respeto que le merece dicha tradición, la deconstrucción no pertenece a la misma filiación: "Es precisamente esta diferencia la que intento articular, ciertamente no sin dificultades”(p. 179, n 4). Se podría intentar leer este distanciamiento de la noción de Destruktion a partir del proyecto de Rosenzweig que es también el de la desedimentación de la teología, principalmente la instaurada por Lutero y su traducción de la Biblia ${ }^{14}$, a partir de lo que llama la Nueva Filosofía que, en La estrella de la redención opone al "paulinismo de Lutero"

${ }^{12}$ Benjamin Pollock ha explicado bien esta paradoja entre la manifestación y la alteración que acontece en la Revelación. (Pollock 2014a, 185-87)

13 "Del hecho de que la revelación esté dotada de una dirección clara y unívoca, en tanto que es amor derramado por Dios sobre el hombre, no se sigue que éste sea pura pasividad, es decir, que sea el propio Dios quien saque al sí-mismo de su obstinado estar vuelto sobre sí mismo, del ensimismamiento que le caracteriza como facticidad irrelativa. Es el propio Selbst el que sale de su orgullosa cerrazón para convertirse, de ese modo, en el otro polo de la revelación, esto es, para convertirse en homo revelationis." (Navarrete Alonso 2017b)

${ }^{14}$ De ahí su proyecto de hacer junto con Buber una nueva traducción de la Biblia al alemán. Ver el texto de Rosenzweig "La Biblia y Lutero" en (Rosenzweig 2007). Ver también el texto que Marc Crépon le dedicó a esta cuestión (Crépon 2010) 
como el intento del reformista de "dar a la fe apoyo objetivo basándola en el pasado de que dan testimonio la Escrituras.”(Rosenzweig 1997, 142) Mientras que en la Nueva Filosofía - que va de mano de la teología- "se trata de volver a engarzar en el concepto de Creación a la Revelación misma, en tanto que vinculada con y basada en la confianza en la venida del reino moral de la Redención final.”(Rosenzweig 1997, 145)

Señalemos rápidamente que la Creación es la relación de Dios con el mundo, la Revelación la del hombre con Dios, y la Redención la del hombre con el mundo. La crítica a Lutero es la de basar la fe solamente en la Revelación, conjugándola en pasado y de la cual dan testimonio las Escrituras, mientras que, para Rosenzweig, la Revelación es un presente que renueva la Creación, y esto último exige un nuevo racionalismo (título del capítulo que viene a continuación de las frases antes citadas). No se debe creer que esta "Nueva filosofía" rebaja a la filosofía a ser criada de la teología, sino que la prioridad que le da a la filosofía implica entender su noción de Revelación como "[el] puente entre lo más subjetivo y lo más objetivo[...]”(Rosenzweig 1997, 148), pues la Revelación es, ante todo, una vivencia personal que tendrá su corroboración en la Redención como responsabilidad del hombre por el mundo, desde la cual se puede hacer una lectura política de la teología de Rosenzweig.

Dicho esto último, para el filósofo de Kassel la política no es un fin en sí mismo sino que tiene un importante papel en el desarrollo del mundo desde la Creación hasta la Redención (Pollock 2004). Y, dentro de este sistema, la guerra es un vector central, es el inicio de La estrella de la redención con el grito de angustia que la filosofía ignora y por el cual comienza el conocimiento, pero es también la guerra mundial que lleva del imperio del cristianismo al Reino de la Redención. Al hablar de las guerras mundiales en Canallas, Derrida no hace alusión a Rosenzweig sino a la Crisis de Husserl de 1935, que es más bien un texto de entre-guerras, en el que, de modo similar a Rosenzweig, habla de la colusión de Estados-naciones en un momento en que la soberanía del Estado-nación indivisible estaba sometida a una prueba más que crítica; como lo resume Derrida: "Dicha prueba demuestra más o mejor que nunca [...] a la vez la fragilidad de la soberanía del Estado-nación, su precariedad, el principio de ruina que lo trabaja - y, por consiguiente, la denegación crispada, con frecuencia asesina, de sus sobresaltos o coletazos de agonizante"(Derrida 2005, 184). Esta fragilidad tiene dos caras, por un lado, como ocurrió después de las dos guerras mundiales, se crearon organizaciones, instituciones de derecho penal y estructuras gubernamentales trasnacionales para contrarrestar la soberanía de los Estados-nación, aunque siempre con sus limitaciones. Por el otro lado, hemos sido testigos de una mundialización de la guerra, del terrorismo y del enemigo que ha señalado la inmu- 
nidad del Estado-nación. Otro aspecto común a Rosenzweig y Derrida es justamente la crítica a la mundialización ${ }^{15}$, entendida como una visión teológica del espacio y del tiempo, así como la postulación de una ontología de la ruina que trabaja a la soberanía.

La herencia de Rosenzweig en Derrida - y también en Levinas -, es que llegar a los fines del Estado, a diferencia de Hegel, para quien la realización del Espíritu está en el Estado secular ${ }^{16}$, implica un nuevo concepto de responsabilidad como heteronomía. Siguiendo la lectura que Derrida hace de la Crisis de Husserl, la mundialización es una pérdida de mundo, pérdida del fundamento, pérdida de la referencia y del mundo como sentido. ${ }^{17}$ En pocas palabras, es la condición de weltlos: "en este abismo del sin-mundo donde, sin soporte, y a condición de esta ausencia de base, de fondo, de suelo y de fundamento, es como si uno portase al otro, como si yo me sintiese, sin soporte ni hipótesis, portado por el otro y portado hacia el otro, allí donde, como dice Celan, Die Welt is fort, ich muss dich tragen, el mundo se va, el mundo desaparece, te tengo que portar [...]"(Derrida 2005, 185). El verso de Celan, que Derrida cita en distintos momentos, podría quizás interpretarse a partir de la experiencia de la Revelación que, al llegar a los fines del Estado y de la guerra mundial, se ve arrojada a una responsabilidad por el otro, ahí donde no hay soporte, ahí donde el mundo se desvanece.

Se trata de una noción de responsabilidad contraria a la deontología kantiana; la heteronomía podría pensarse como un portar al otro a pesar de sí, por sobre la soberanía del ipse. Esto último puede ser un primer aspecto para entender

${ }^{15}$ Roberto Navarrete ha mostrado que en el escrito de Rosenzweig, "Globus", un texto de juventud que data de 1917, la cuestión de fondo es la mundialización. Dicho texto fue escrito después de la entrada de los Estados Unidos y Japón en la Primera Guerra Mundial y por lo tanto, su entrada a la historia mundial que dejaría de ser puramente europea. En este sentido, la redención implicaría la globalidad del globo terráqueo sin fronteras en un más allá de la historia universal. La diferencia con el Großraum-Lehre de Schmitt, explica Navarrete, es que el jurista alemán apuesta por un katechon como el balance de poderes políticos en la historia universal mientras que para Rosenzweig la política puede interrumpir el eschaton como redención. En Derrida, encontramos una reflexión sobre la mundialización de las religiones monoteístas o, como él la llama, la latinomundialización, una alianza entre el cristianismo como experiencia de la muerte de Dios y el capitalismo tele-tecnocientífico que impone su hegemonía. En este sentido, la globalizaión que propone Rosenzweig desde el judaismo como redención, es opuesto a la latinomundialización como globalización o totalización. (Navarrete Alonso 2017a)

16 Por ejemplo, en el §539 La enciclopedia: "El estado, como espíritu simplemente viviente [que es], tan sólo es siendo un todo organizado y diferenciado en las distintas actuaciones eficaces particulares que, procediendo del concepto único de voluntad racional (aunque no conocido como concepto), producen continuamente el estado como resultado suyo."(Hegel 2017, 873) P.873

${ }^{17}$ Encontramos en Walter Benjamin una reflexión similar sobre las consecuencias de la Segunda Guerra Mundial, donde la pérdida de mundo es la pérdida de la capacidad para expresar la experiencia: "Con la Guerra Mundial comenzó a hacerse evidente un proceso que desde entonces no ha llegado a detenerse. ¿No se advirtió que la gente volvía enmudecida del campo de batalla? No más rica, sino más pobre en experiencia comunicable.”(Benjamin 2016, 52) 
la noción de "decisión pasiva" como una libertad sin autonomía y una heteronomía sin servidumbre que, a mi parecer, están en deuda con la noción rosenzweiguiana de Revelación. Al mutismo del héroe pagano, Rosenzweig le opone un Yo que está habitado por una alteridad y que recuerda la fórmula levinasiana de la subjetividad: "l'autre dans le même"(Levinas 2004, 32). "Al Yo le responde en lo íntimo de Dios un Tú. Es el acorde de Yo y Tú en el monólogo o autodiálogo de Dios cuando crea al hombre" (Rosenzweig 1997, 220). No obstante, la autenticidad sólo aparecerá cuando ese Tú se vuelve exterior: "Solo cuando el yo reconoce al Tú como algo exterior a él mismo, o sea sólo cuando del monólogo se pasa al diálogo auténtico, se torna ese Yo que hemos pretendido hace un momento que es el No originario pronunciado en alta voz" (Rosenzweig 1997, 220). El diálogo marca una ruptura con la razón cartesiana y su suspensión del Mundo que asume la certeza de la ipseidad en el monólogo solipsista de la razón. En Rosenzweig hay una gramática, propia de la Revelación, en la que el Yo se diferencia del todo con un No originario, que le revela su singularidad.

La alteridad sólo se puede explicar porque la Revelación es un acontecimiento - en el sentido derridiano; el milagro que Rosenzweig describe en términos de un acontecimiento: ereignetes Ereignis. Recordemos que, para el autor de la Estrella, el milagro es signo que se conjuga en el instante. El mandamiento del amor es un imperativo que, subraya: "es presente absolutamente puro y sin preparativos. No sólo sin preparativos, sino incluso sin premeditación. El imperativo del mandamiento no hace previsiones para el futuro: lo único que se puede representar es la instantaneidad de la obediencia."(Rosenzweig 1997, 223) En cierto sentido, esto recuerda lo incalculable de la decisión pasiva, que sería también, como el llamado del amado, un acontecimiento según lo describe Derrida: "Allí donde no hay esa singularidad absoluta de lo incalculable y de lo excepcional, nada ni nadie, nada distinto ni, por lo tanto, nada ocurre. Digo "nada ni nadie" para volver a un pensamiento del acontecimiento que se despabila o despierta antes de distinguir o de conjugar el 'qué' o el 'quién'”(Derrida 2005, 176). Antes de conjugar el "qué" o el "quién" porque justamente la Revelación o la decisión pasiva rompen con la idea metafísica de sujeto en tanto que entidad autónoma que toma decisiones. Derrida explica en Fuerza de ley "[...] un sujeto es precisamente aquello a lo que una decisión sólo puede llegar como accidente periférico que no afecta ni a la identidad esencial ni a la presencia a sí sustancial que hacen del sujeto un sujeto [...]"(Derrida 2002, 56). Precisamente, la Revelación es lo que hace que el alma se descubra y a su vez se altere rompiendo con la idea de identidad y de sustancia. A su vez, el presente de un acontecimiento que llama, según Rosenzweig, desde el nombre propio "se trata de un singular sin género. En el lugar del artículo, lo que hay es la determinación inmediata del nombre propio"(Rosenzweig 1997, 233). Tanto en Rosenzweig como en Derrida hay una 
filosofía sobre la singularidad del nombre propio $^{18}$, es justamente la Revelación lo que da lugar a la singularidad y al hecho de que el nombre propio no sea un genérico, sino a partir del cual, el alma es interpelada desde su singularidad.

De acuerdo con Rosenzweig, el Yo sólo es auténtico cuando a la pregunta de Dios ¿dónde estás?, el alma responde ¡aquí estoy! (hineni) lo que recuerda la respuesta de Adán en el Génesis después de comer del árbol del bien y del mal. El Yo se descubre como responsable ante el Tú. La libertad sin autonomía y la heteronomía sin servidumbre de la decisión pasiva la podemos leer en el mandamiento del amor que es el opuesto a la noción tradicional de decisión y de libertad, en esta aparente paradoja que formula Rosenzweig según la cual el amor es mandamiento: "debes amar" en vez de un "puro libre regalo" (p.222). La paradoja que Rosenzweig ilustra con el Cantar de los cantares reside en que no se puede obligar a amar, pero en este caso, el amor viene de la voz del amante. En realidad, lo que encontramos en el mandamiento del amor es un desplazamiento del concepto de libertad, por lo cual podemos entender el sentido de la heteronomía (la ley o el nomos que viene del otro), una obediencia sin servidumbre hacia la voz del amante que se conjuga siempre en imperativo: "Si estuviera pensado en el futuro o en siempre, no sería mandamiento ni orden, sino ley"(Rosenzweig 1997, 223). El mandamiento implica entonces la pasividad en el oír tal como lo describe Rosenzweig: “Aquí está el Yo. El Yo singular humano. Está todo él recepción, apertura, vacío, sin contenido, sin esencia: pura disposición, pura escucha y obediencia, todo él oídos. En este oír obediencial cae como primer contenido el mandamiento"(Rosenzweig 1997, 222). Pero este mandamiento que pide una obediencia pasiva se enuncia: "Ámame”, se trata de un amor que implica la singularidad del Yo y su palabra "La obediencia al mandamiento no puede permanecer muda. Tiene también que sonar; también que hacerse palabra. Pues en el mundo de la Revelación todo se vuelve palabra [...]"(Rosenzweig 1997, 224). Así, la Revelación implica la alteridad como apertura de la ipseidad tanto como la del tiempo. Es una alteración pues el alma llega a ser ella misma, a la vez que se descubre amada y vulnerable, o como escribe Rosenzweig "Por ello no le es fácil al alma la confesión de amor. Al hacerla, se desnuda”(Rosenzweig 1997, 225).

Por otro lado, el mandamiento del amor es una decisión pasiva que está más allá de la razón, heterogénea al orden de lo calculable, tal como lo plantea Derrida en su noción de indecidible, pero también como lo describe Rosenzweig:

${ }^{18}$ La cuestión sobre nombre propio vuelve una y otra vez en la obra de Derrida, en parte por la importancia que le da a pensar la singularidad pero también porque el nombre propio que permite la interpelación, nunca es propio. Podemos encontrar reflexiones sobre el nombre propio en De la gramatología, cuando reflexiona sobre la prohibición de los Nambikwaras de revelar el nombre propio y la trampa que hace el etnólogo para descubrirlos. Ver también Circunfesión. El nombre propio se relaciona también a la noción de firma en Limited Inc, lo encontramos también en sus lecturas de Ponge, así como en Schibboleth para Paul Celan, en su texto Otobiografías. La enseñanza de Nietzsche y la política del nombre propio entre otros. 
"La declaración amorosa [die Liebeserklärung] es muy pobre; como todas las declaraciones [wie jede Erklärung], siempre llega después y, por tanto, como el amor del amante es presente, siempre, en realidad, llega demasiado tarde.”(Rosenzweig 1997, 222) La declaración del amor no tiene explicación ${ }^{19}$, está más allá de la razón calculante porque es un evento único. Me parece que la cercanía entre Rosenzweig y Derrida reside en el hecho de que la hyper-ética o la metaética conducen a una política de la singularidad (a diferencia de Levinas quien, a mi parecer, permanece más bien en la ética hiperbólica).

Precisamente el sentido de "meta" en la metaética que Rosenzweig introduce en la Estrella de la redención, no se dirige al hombre en general, ni siquiera al individuo: "No se trata de una individualidad que se separe de otras individualidades; no es una parte, mientras que el individuo confiesa, justamente al aferrarse a su indivisibilidad, que él mismo es una parte. Este ser propio del hombre no es de suyo infinito, sino que es en lo infinito. Es singular y, sin embargo, lo es todo"(Rosenzweig 1997, 105). La singularidad es el acontecimiento del llamado a la unicidad de cada uno, no es en este sentido un pensamiento de la pluralidad sino del papel que cada uno, en primera persona pero a coro, tiene en la Redención. La singularidad es también, como lo enfatiza Derrida, el corazón de la cuestión de la justicia; así lo expresa en Fuerza de ley, formulación que no carece de ecos mesiánicos: "[...] infinita, infinita porque irreductible, irreductible porque debida al otro; debida al otro, antes de todo contrato, porque ha venido, es la llegada del otro como singularidad siempre otra"(Derrida 2002, 58).

La justicia para Derrida implica la "singularidad incalculable y excepcional"(Derrida 2005, 176), es decir, no es una regla ni una ley o una norma en la que un caso pueda caer, sino un acontecimiento. La pregunta permanece y se formula sobre por qué esta política de la singularidad deconstruye la soberanía. Como hemos intentado mostrar, la relación de la decisión pasiva y la revelación de la singularidad, que implica el acontecimiento del llamado y una respuesta que no supone una decisión, no es reapropiable "por la ipseidad de un poder soberano y de un saber calculable"(Derrida 2005, 176). Esto no reapropiable por una voluntad puede ser entendido desde el mandamiento del amor de Rosenzweig. A su vez, esto no reapropiable señala la auto-inmunidad de la razón que "[...] no es un mal absoluto. Permite la exposición al otro, a lo que viene y a quien viene $-\mathrm{y}$ debe pues permanecer incalculable. Sin auto-inmunidad, con la inmunidad absoluta, nada ocurriría ya"(Derrida 2005, 182). La auto-inmunidad es un concepto que Derrida retoma de la biología y que alude a un tipo de comportamiento por el cual el ser vivo se autodestruye por una vulnerabilidad relativa a sus propias defensas, que el filósofo francoargelino utiliza como una metáfora para describir

${ }^{19}$ García-Baró traduce Lebenserklärung (Rosenzweig 1988, 196-97) por declaración amorosa, lo que pierde el doble sentido de explicación. En inglés Barbara E. Galli lo traduce por "the explanation of love" p.191. 
tanto a la ipseidad -en su dimensión no solo de sujeto sino de viviente-, como del espacio de la autoridad o del Estado-nación y sus fronteras. La auto-inmunidad implica, tanto como la Revelación, una exposición al otro que no se reduce al saber porque conlleva la vulnerabilidad y la mortalidad, que Rosenzweig reclama desde las primeras páginas de la Estrella contra una filosofía que habla de un "cuerpo" entre comillas (Rosenzweig 1997, 43). Mientras que el acontecimiento que afecta a una pasividad, dice Derrida, "debe atañer a una vulnerabilidad expuesta, sin inmunidad absoluta, sin indemnidad, en su finitud y de una forma no horizontal, allí donde todavía no es o ya no es posible enfrentarse a, ni afrontar, la imprevisibilidad del otro.”(Derrida 2005, 182)

Lo interesante de lo que apunta Derrida, y que me parece que resume lo inédito de la Revelación de Rosenzweig, es que esta última también se refiere al Dios como el amante que depone su potencia soberana: "Al hablar de una ontoteología de la soberanía, me refiero, bajo el nombre de Dios, del Dios Uno, a la determinación de una omni-potencia soberana y, por ende, indivisible. Pero allí donde el nombre de Dios daría a pensar otra cosa, por ejemplo, una no-soberanía vulnerable, doliente, divisible, mortal incluso, capaz de contradecirse o de arrepentirse $[\ldots]$ se trataría de una historia bien distinta, y quizá la de un dios que se deconstruye, inclusive en su ipseidad"(Derrida 2005, 187). Para Rosenzweig, Dios no es una tautología sino el Dios que se revela en la experiencia amorosa; hay una revolución teológica porque el Dios de la revelación está pensado desde la pasividad (en el sentido del pathos y de la apertura), no desde una razón soberana o desde una omni-potencia indivisible. Sin embargo, lo importante en el Sistema de la Estrella es la relación entre todos los elementos, Dios, Hombre y Mundo como Creación, Revelación y Redención; por lo cual, la revelación sólo puede completarse como redención del hombre con el mundo y con todo lo viviente: "El milagro fundamental de la Revelación, que ocurrió una vez en el pasado, exige completarse con otro milagro ulterior, que aún no ha sucedido. El Dios que llamó por su nombre un día al alma - cosa que, como todo lo pasado, 'consta', pero no ha llegado a conocimiento de ningún tercero -, tiene que 'volver a hacerlo', pero ahora ante los ojos de todo lo que vive.’(Rosenzweig 1997, 231) y esto último nos conducirá a la política mesiánica que Rosenzweig presenta en la tercera parte de la Estrella.

\section{LA POLÍTICA MESIÁNICA Y EL POR-VENIR DE LA RAZÓN}

Habría otra manera de leer la noción de decisión pasiva desde la filosofía de Rosenzweig, principalmente a partir la política mesiánica que expone en el tercer libro de La estrella de la redención, en donde contrapone una temporalidad que marca la autoconservación por la guerra, a la temporalidad del pueblo eterno. Este último está fuera del tiempo de los pueblos del mundo, del tiempo cronológico; vive la temporalidad marcada por el calendario litúrgico, pero también en 
el instante mesiánico en el que entre "el instante presente y el cumplimiento final ningún tiempo puede ya reclamar sitio: en el hoy puede ya asirse todo el futuro"(Rosenzweig 1997, 389).

Derrida no menciona al filósofo de Kassel en el apartado de Canallas, Llegar-A los fines del Estado (y de la guerra y de la guerra mundial), si bien el título mismo ya contiene ecos de la filosofía de Rosenzweig, comenzando por su disertación sobre Hegel y el Estado, ${ }^{20}$ que inició en 1908 bajo la dirección de F. Meinecke y se publicó en 1920, en donde analizó la Primera guerra mundial como una colusión de estados-nación soberanos, en la cual se hacían visibles las consecuencias de la visión hegeliana de la historia, que lo condujo a apoyar la creación de un espacio llamado Centroeuropa (Mitteleuropa) que imagina como un imperio donde Judaísmo y Cristianismo jugaran un papel importante en la disolución del Estado nación. Su preocupación por la cuestión de la soberanía lo confirma "Globus", un texto compuesto en 1917 en el que menciona específicamente al profeta Isaías y concibe el inicio de la historia universal como el establecimiento de la primera frontera, historia que se vería contrariada en la guerra mundial por un cambio en la topografía geopolítica a causa de la confrontación entre los imperios y, que se decantaría en los tiempos mesiánicos con una configuración parecida a la de los océanos, sin Estados ni fronteras: "La humanidad se hizo con la posesión de la tierra mediante el establecimiento de la primera frontera. Toda la historia universal no es sino el desplazamiento de aquella primera frontera, no es sino el siempre renovado desplazamiento recíproco de lo mío, lo tuyo, lo suyo [...]"'(Rosenzweig 2015, 117) En cierta manera, las fronteras de los Estados-Nación según Rosenzweig, tienen su origen en la ipseidad como posesión y apropiación de "lo mío" frente a la posesión de la segunda y la tercera persona.

La solución que da en Globus es la desaparición de las fronteras: "La ausencia de fronteras, que constituye la meta última de la Tierra, es lo propio del mar desde el principio. En el mar la naturaleza pone ante los ojos del hombre la imagen de la unidad que él mismo debe imprimir en la tierra por medio del duro trabajo de su diaria labor histórico-universal."(Rosenzweig 2015, 118) Me parece que este fin de la historia como fin de las fronteras se debe leer como una nueva manera de concebir una política de la redención y, por lo tanto una deconstrucción de la soberanía que implica una labor diaria y no excepcional, con carácter histórico-universal. Esta posición de Rosenzweig podría pensarse desde la hospitalidad incondicional que es un ejemplo que el mismo Derrida pone de una incondicionalidad sin soberanía ${ }^{21}$, si bien no plantea la desaparición de fronteras,

${ }^{20}$ (Rosenzweig 2010) No existe traducción al español de Hegel und der Staat, se puede encontrar una traducción al italiano y una versión al francés de Gérard Bensussan.

${ }^{21}$ En Canallas escribe: "Entre todas las figuras de la incondicionalidad sin soberanía que alguna vez he privilegiado estos últimos años, estaría por ejemplo la de la hospitalidad incondicional que se opone sin límite a la venida del otro, más allá de la hospitalidad condicionada por el derecho de asilo, por el derecho a la inmigración, por la ciudadanía e incluso por el derecho a 
expone una hospitalidad que comenzaría cuestionando el sí mismo como en casa. En Adiós a Emmanuel Levinas, relaciona la hospitalidad incondicional con la decisión y la responsabilidad, mostrando a la vez su distancia con Levinas según comienza la frase:

"Lévinas no lo diría de esta manera, sin duda, pero ¿no se puede sostener así que, sin exonerarme de nada, la decisión y la responsabilidad son siempre del otro? ¿Que ellas corresponden siempre al otro, vienen del otro, aunque fuese del otro en mí? Ya que, finalmente, ¿sería aún una decisión, la iniciativa que permaneciera pura y simplemente 'mía', conforme a la necesidad que, en la más potente tradición de la ética y de la filosofía, parece no obstante requerir que la decisión sea siempre 'mi' decisión, la decisión de quien puede decir libremente 'yo', ipse, egomet ipse? ¿Sería aún una decisión, lo que así me atañe? ¿Se tiene derecho a dar ese nombre, 'decisión', a un movimiento puramente autónomo, aunque fuese de acogida y de hospitalidad, que sólo procediera de mí, de mí mismo, y no hiciera sino desplegar los posibles de una subjetividad mía?" (Derrida 1998, 41-42)

La noción de hospitalidad incondicional muestra muy bien la manera en que Derrida relaciona la deconstrucción de la subjetividad y, por ende, de la decisión libre, del "yo puedo" con la soberanía, pues la hospitalidad es ante todo un problema de fronteras y de derecho político. En Canallas, vuelve sobre la discusión con Kant, pero esta vez en el sentido de la racionalidad: "Una hospitalidad incondicional es la única que puede dar su sentido y su racionalidad práctica a cualquier concepto de hospitalidad. La hospitalidad incondicional excede el cálculo jurídico, político o económico"(Derrida 2005, 178). La pregunta es ¿cómo esta hospitalidad y racionalidad incondicional pueden ser traducidas en una política que no las relegue a un malabarismo intelectual? Como lo señala Derrida en La bestia y el soberano, la soberanía no tiene opuesto, y por lo tanto un futuro sin soberanía sería la última ficción ${ }^{22}$. De lo que se trata es entonces de pensar distintas maneras de trabajar con el resto y de imaginar políticamente la incondicionalidad sin soberanía. Es a partir de esta problemática que quisiera abordar la política mesiánica de Rosenzweig.

En La estrella de la redención, Rosenzweig desarrolla una política mesiánica que inicia con "una teoría de la guerra" (Rosenzweig 1989, 73) donde argumenta que los pueblos del mundo que buscan la expansión imperialista entran en guerra porque se tienen a sí mismos por mortales; se trata en todo caso de una

la hospitalidad universal del que habla Kant y que sigue estando controlado por un derecho político o cosmopolítico."(Derrida 2005, 177-78) En este mismo texto añade una larga nota a pie de página sobre distintas obras en las que trata la cuestión de la hospitalidad incondicional.

${ }^{22}$ Ver Capítulo 1 de (Derrida 2010) 
lógica de auto-inmunidad, de una dialéctica entre auto-conservación y la posibilidad de extinción. Rosenzweig presenta entonces un sentido más bien metafísico de la guerra, pues mientras un pueblo relaciona con mayor seriedad la unión de salus y fides, "de existencia propia y propio sentido para el mundo, tanto más enigmática se le vuelve la posibilidad que la guerra le abre: la posibilidad de sucumbir. Por esto la guerra le retrotrae al centro de su vida"(Rosenzweig 1997, 391). En el primer caso, Rosenzweig contrapone a la figura de Sigfrido ${ }^{23}$ como la alegoría de los pueblos del mundo frente al judío, el primero guiado por un mito pagano que lo apartaba de Dios y del prójimo por vivir en el tiempo de guerras y el pueblo judío que vive fuera de esa dialéctica en una conversión del amor revelado que, según Rosenzweig, no hace "escisión entre lo más propio y lo supremo: para él, el amor a sí mismo se hace inmediatamente amor al prójimo." (Rosenzweig 1997, 390)

Rosenzweig critica la unión que hace el cristianismo entre el pueblo y el Estado, con base en la declaración de San Agustín de que para la Iglesia no puede haber escisión entre la autoconservación que es la apuesta de la guerra, y la fe, por lo cual, salus y fides son la misma cosa. El nacionalismo viene de una cierta relación con el tiempo, con la idea de elección mal entendida, pues los pueblos del mundo ponen la eternidad en un amor propio que tiene el miedo de un futuro lejano en el que pudieran desaparecer. De ahí que el Estado y la guerra sean el centro de sus vidas, porque siempre está la posibilidad de sucumbir. No obstante, para el filósofo de Kassel, el cristianismo habría logrado como proyecto la mundialización como un borramiento de fronteras: "Conforme al espíritu del cristianismo, que ya no sufre fronteras, no hay para ellos pueblo alguno que sea 'muy lejano'. La distinción del derecho político judío entre guerra religiosa y guerra del estado se le confunde en una sola cosa"(Rosenzweig 1997, 392). De manera que si bien hay un proyecto de mundialización en el Cristianismo como unión universal de salus y fides, el borramiento de fronteras tiene como telón de fondo la guerra religiosa, mientras que, escribe Rosenzweig, "el pubelo judío ha dejado tras sí, en el pasado mítico, su guerra religiosa. Por esto, cuantas guerras aún le toca vivir son para él nada más que guerras políticas."(Rosenzweig 1997, 392) Y estas guerras políticas, aclara, no se las toma en serio, por eso es el único pacifista auténtico. Este no tomarse en serio la guerra política resulta de vivir en un tiempo que no depende del resguardo de la vida del pueblo a lo largo del curso de la historia del mundo sino de una vivencia, en el año liturgico, que es a la vez el

${ }^{23}$ Que describe en términos raciales como un ario que se opone al judío: "Entre los pueblos del mundo se ha producido una discordia desde que ha venido a ellos la potencia supranacional del cristianismo: desde entonces hay en todas partes un Sigfrido que lucha con esta extraña figura, que ya le es sospechosa por su aspecto, del hombre crucificado: un hombre rubio y de ojos azules, o negro y de ágiles miembros, o moreno y de ojos oscuros, como nosotros mismos, que combate contra este extranjero que se resiste a todos los intentos siempre repetidos por adecuarse a la imagen deseada de sí mismo. Sólo para el judío no hay disensión entre la más alta imagen puesta ante su alma y el pueblo al que su vida le lleva.”(Rosenzweig 1997, 290) 
acontecimiento de lo que podríamos llamar una política de la singularidad "[...]la inmediatez de todos los individuos a Dios en la comunidad perfecta de todos con Dios"(Rosenzweig 1997, 393).

La teología política de Rosenzweig es contraria al Estado que supone la violencia del derecho. Rosenzweig presenta en La estrella de la redención un argumento sorprendentemente similar al que Walter Benjamin desarrolla en "Para una crítica de la violencia"(Benjamin 2001) cuando Rosenzweig sostiene "El sentido de toda violencia es fundar un nuevo derecho [Es ist der Sinn aller Gewalt, dass sie neues Recht gründe]"(Rosenzweig 1997, 394; 1988, 370). Es difícil demostrar la influencia de un autor en el otro, pues los dos textos ven la luz en 1921. Sin embargo, no podemos pasar de largo algunos paralelismos, ya que Rosenzweig también habla de una violencia renovadora del viejo derecho: "A cada instante solventa con violencia el estado la contradicción entre conservación y renovación, viejo y nuevo derecho.”(Rosenzweig 1997, 395) Lo que parece una similitud con la oscilación benjaminiana entre una violencia fundadora y una violencia conservadora de derecho, si bien en este punto, Derrida es más cercano a Rosenzweig cuando sostiene que ellas se confunden ${ }^{24}$, y que en Fuerza de ley describe como una distinción que se auto-deconstruye, que se arruina $^{25}$ y se contamina (Derrida 2002, 107-8). No obstante, Derrida no hace ahí ninguna referencia al filósofo de Kassel. Esta renovación del derecho en la conservación no sólo garantiza al Estado, según Rosenzweig, sino también a la historia universal: "sin estado no hay, pues, historia del mundo, historia universal"(Rosenzweig 1997, 396) ["Ohne Staat also keine Weltgeschichte"] (Rosenzweig 1988, 371)].

De ahí que el pueblo judío aspire a una eternidad ajena al Estado y a la historia universal. De hecho, como señala Santner, la soberanía del Estado es, para Rosenzweig, un modo de vivir la temporalidad, mientras que la Revelación es un despertar violento del tiempo de la guerra y de la historia (Santner 2001, 64-65). Sin embargo, esta revelación que interrumpe la temporalidad soberana,

\footnotetext{
${ }^{24}$ Como bien lo plantea Rodolfo Navarrete, la diferencia con Rosenzweig es que desde el principio hace de la renovación y la conservación algo indistinguible y sostiene que la idea de derecho nuevo es una contradicción. La ignominia que Benjamin atribuía a la policía se la hace corresponder Rosenzweig al Estado más de medio siglo antes que Derrida. La empresa del Estado, la introducción de la eternidad en el tiempo, o la retención katechóntica de la historia, consiste para el autor de la Estrella, justamente, en la resolución, a cada instante, de "la contradicción entre lo viejo y lo nuevo gracias a la renovación violenta de lo viejo, que presta a lo nuevo la forma jurídica de lo antiguo", fundiéndose con ello "al consolidarse osadamente en un "nuevo derecho"'. Sólo así retiene el movimiento que se escapa: el tiempo; y sólo así es posible hablar de épocas históricas." (Navarrete Alonso 2019, 75)

${ }^{25}$ Derrida expone en este texto una ontología de la ruina en el pensamiento de Benjamin: "La ruina no es a mis ojos una cosa negativa. En primer lugar, evidentemente, no es una cosa. Se podría escribir, quizás con o según Benjamin, quizás contra Benjamin, un breve tratado del amor de las ruinas.”(Derrida 2002, 109) Podríamos aplicar esto a Rosenzweig y decir que la historia mundial es la historia de las ruinas. Sobre la ontología de la ruina en Rosenzweig y Derrida ver: (Bensussan 2003)
} 
está ligada a la redención que, a diferencia de la coerción por la violencia ( $G e-$ walt) de la ley, lo hará en el nosotros del coro que Rosenzweig presenta como la lengua de la Redención. El pueblo eterno permanece ajeno al Estado y a la historia universal, pero no ajeno al mundo ${ }^{26}$, en el sentido en que la Redención se confirma en la Creación, lo que conlleva un compromiso con la vida: "Sólo el nuevo instante rompe la violencia del viejo y amenaza con volver a dejar fluir libremente la corriente de la vida"(Rosenzweig 1997, 396). Es quizás a partir de esta temporalidad mesiánica que podemos pensar las últimas líneas del texto de Benjamin sobre la violencia que puede llamarse soberana (die waltende heissen), que nunca es instrumento de sacra ejecución y que reconoce la sacralidad de la vida justa.

En sus obras de finales de los '90 y principios del 2000, Derrida retoma una noción de mesianismo que, por un lado, cuestiona la justicia pensada en el horizonte del derecho; por el otro, plantea una política de la singularidad muy parecida a la que nos ofrece Rosenzweig. Comenzando con Espectros de Marx (1994), pero también en obras posteriores, Derrida desarrolla una noción de lo mesiánico que describe como "la venida del otro, la singularidad absoluta e inanticipable del y de lo arrivante (l'arrivant) como justicia"(Derrida 1995, 42). Esta noción de mesianicidad está ligada a un futuro no calculable ni predecible y que Derrida describe como una "espera sin horizonte de espera", que también relaciona con una "fe hipercrítica", contraria a toda escatología. En Espectros de Marx, Derrida vincula lo indeconstructible, como posibilidad de la deconstrucción, a lo mesiánico: "Cierta experiencia de la promesa emancipatoria; puede ser, incluso, la formalidad de un mesianismo estructural, un mesianismo sin religión, incluso un mesiánico sin mesianismo, una idea de la justicia —que distinguimos siempre del derecho e incluso de los derechos humanos - y una idea de la democracia - que distinguimos de su concepto actual y de sus predicados tal y como hoy en día están determinados_-”(Derrida 1995, 73).

La cuestión es ahora ¿cómo enfrentarse a la soberanía, una, del Estadonación? Derrida afirma en Canallas: "No se puede combatir, y de frente, toda soberanía, la soberanía en general, sin amenazar por las mismas, aparte de la figura estatalnacional de la soberanía, los principios clásicos de libertad y de autodeterminación"(Derrida 2005, 187). Esta es indudablemente la herencia de Rosenzweig en Derrida, la de una libertad pasiva que no exonera de la responsabilidad. Me permito citar in extenso un diálogo con Roudinesco que resume muy bien la noción de decisión pasiva:

${ }^{26}$ Esto es para Rosenzweig uno de los "peligros judíos": "Ardiendo hacia dentro, el judaísmo amenaza con concentrar su calor en su propio seno, alejándose de la realidad mundanal pagana. Si allí [en el cristianismo] los riesgos eran la espiritualización de Dios, la humanización de Dios y la mundanización de Dios, aquí son la negación del mundo, el desprecio del mundo y el darle muerte al mundo.”(Rosenzweig 1997, 476) Agradezco a Roberto Navarrete recordarme este capítulo de la Estrella y la advertencia de Rosenzweig del peligro de caer en el marcionismo. 
"Por eso a menudo digo, y trato de demostrar, en qué 'mi' decisión es y debe ser la decisión del otro en mí, una decisión 'pasiva', una decisión del otro que no me exonera de ninguna responsabilidad. Proposición escandalosa para el sentido común y para la filosofía, pero cuya necesidad ineluctable e implicaciones creo que racionalmente (no puedo hacerlo aquí) es posible demostrar. Cuando digo 'racionalmente', a todas luces apelo a una historia de la razón, y por tanto también a su por-venir. A (lo) que viene bajo el nombre de razón.” (Derrida y Roudinesco 2009, 63)

La decisión del otro en mí podría ser un sinónimo de la Revelación, de un mandamiento del otro que crea un Tú como respuesta y no exonera de ninguna responsabilidad, sino que abre a una responsabilidad aún más amplia que la que es presentada por su noción tradicional y que incluye no sólo al prójimo, sino a todo lo viviente. Esto último me parece que es el mesianismo estructural del que habla Derrida, uno abierto al incalculable arribo del otro y de lo otro, por encima de toda soberanía, ya sea del ipse o de un territorio y sus fronteras.

En cierto sentido, combatir a la soberanía amenaza a la razón práctica como auto-determinación: la decisión pasiva implica una alteridad y alteración de la razón como Revelación, pero también una ruptura con la temporalidad histórica a partir de un acontecimiento - que podría recordar la noción benjaminiana de debil fuerza mesiánica "schwache messianische Kraft”'(Benjamin 1980, 694). Este acontecimiento es la negación de la soberanía pensada desde la herencia de un Dios omnipotente e indivisible por un Dios amante, que permitiría pensar lo político más allá del Estado-nación y la auto-inmunidad de toda democracia, o tal como lo propuso Rosenzweig, más allá de las fronteras espaciales y temporales de la marcha de la historia. 


\section{BIBLIOGRAFIA}

Batnitzky, Leora. 2000. Idolatry and Representation: The Philosophy of Franz Rosenzweig Reconsidered. NJ: Princeton University Press.

- 2007. «Franz Rosenzweig on Translation and Exile». Jewish Studies Quarterly 14: 131-43.

Benjamin, Walter. 1980. "Über den Begriff der Geschichte". En Gesammelte Schrifften, BD I-II, 691-704. Frankfurt am Main: Suhrkamp.

- 2001. Para una crítica de la violencia y otros ensayos. Iluminaciones IV. 3. ${ }^{\text {a }}$ ed. Madrid: Taurus.

- 2016. El Narrador. Traducido por Pablo Oyarzun. Santiago de Chile: Metales pesados.

Bensussan, Gérard. 2003. "Le dernier, le reste... (Derrida et Rosenzweig)". En Judéités. Questions pour Jacques Derrida, editado por Joseph Cohen y Zagury-Orly, 43-58. Paris: Galilée.

Crépon, Marc. 2001. Les promesses du langage. Paris: Vrin.

—. 2010. "La herencia de las lenguas". Acta Poética 31 (1): 9-30.

Derrida, Jacques. 1995. Espectros de Marx. El estado de la deuda, el trabajo de duelo y la nueva internacional. Madrid: Trotta.

-1997. El monolingüismo del otro. Buenos Aires: Manantial.

-1998. Adiós a Emmanuel Levinas. Palabras de acogida. Madrid: Trotta.

- 2002. Fuerza de ley. El fundamento místico de la autoridad. Madrid: Tecnos.

- 2005. Canallas. Dos ensayos sobre la razón. Madrid: Trotta.

- 2010. La bestia y el soberano. Volúmen I (2001-2002). Buenos Aires: Manantial.

Derrida, Jacques, y Élisabeth Roudinesco. 2009. Y mañana, qué... 2. ${ }^{\mathrm{a}}$ ed. Buenos Aires: FCE.

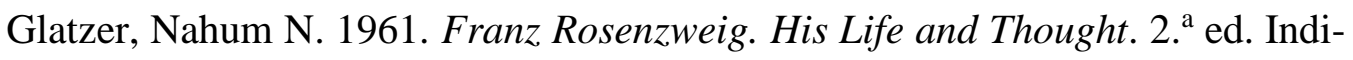
anapolis/Cambridge: Hackett Publishing Company.

Gordon, Peter Eli. 2003. Rosenzweig and Heidegger : Between Judaism and German Philosophy. Berkeley: University of California Press.

Hegel, G.W.F. 2017. Enciclopedia de las ciencias filosóficas. Traducido por Ramón Valls Plana. Madrid: Abada.

Hollander, Dana. 2008. Exemplarity and Chosenness: Rosenzweig and Derrida on the Nation of Philosophy. Stanford University Press.

Honig, Bonnie. 2007. "The Miracle of Metaphor Rethinking the State of Exception with Rosenzweig and Schmitt". Diacritics, 78-102.

- 2009. Emergency politics. Paradox, Law, Democracy. Princeton/Oxford: Princeton University Press.

Jerade, Miriam. 2015. "El monolingüismo del huésped". Revista Isegoría 53: 661-77. 
Levinas, Emmanuel. 2002. Totalidad e infinito. Ensayo sobre la exterioridad. $6 .{ }^{a}$ ed. Santiago de Chile: Editorial Sígueme.

— 2004. Autrement qu'être ou au-delà de l'essence. Paris: Le livre de Poche.

Navarrete Alonso, Roberto. 2017a. "Globalización y geo(teo)política de la historia universal". Éndoxa 40: 183-202.

- 2017b. Los tiempos del poder. Madrid: Escolar y Mayo.

- 2019. "La psyché judeoalemana ante el derecho y el Estado: Walter Benjamin y Franz Rosenzweig". Revista de Filosofía 44 (1): 61-77.

Pollock, Benjamin. 2004. "From Nation State to World Empire: Franz Rosenzweig's Redemptive Imperialism". Jewish Studies Quarterly 11 (4): 332-53.

- 2014a. Franz Rosenzweig and the Systematic Task of Philosophy. Cambridge: Cambridge University Press.

- 2014b. Franz Rosenzweig's Conversions : World Denial and World Redemption. Bloomington: Indiana University Press.

Rosenzweig, Franz. 1988. Der Stern Der Erlösung. Frankfurt am Main: Suhrkamp.

- 1989. El nuevo pensamiento. Madrid: Visor.

- 1997. La estrella de la redención. Salamanca: Sígueme.

- 2007. Lo humano, lo divino y lo mundano. Escritos de Franz Rosenzweig. Buenos Aires: Lilmod.

- 2010. Hegel Und Der Staat. Frankfurt am Main: Suhrkamp.

- 2015. Escritos sobre la guerra. Salamanca: Sígueme.

Santner, Eric L. 2001. On the Psychotheology of Everyday Life. Reflections on Freud and Rosenzweig. Chicago: The University of Chicago Press.

_. 2005. "Miracles Happen: Benjamin, Rosenzweig, Freud, and the Matter of the Neighbor". En The Neighbor: Three Inquiries in Political Theology, 76-133. Chicago: University of Chicago Press.

Vatter, Miguel. 2016. "Cosmopolitan Political Theology in Cohen and Rosenzweig". Philosophy Today 60 (2). 